\title{
Effect of psychological capital and resistance to change on organisational citizenship behaviour
}

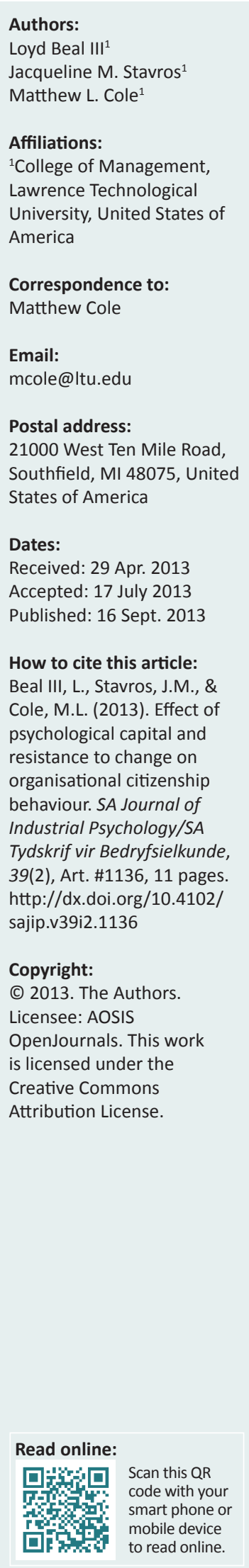

Orientation: Research in positive organisational behaviour shows that positive psychological capital (PsyCap) is a construct that enables self-efficacy, optimism, hope and resilience to succeed in the workplace and that employee resistance to change is a key barrier to organisational change.

Research purpose: This study examined the possible role of resistance to change as a moderator of the predictive relationship between PsyCap and organisational citizenship behaviour (OCB), in which OCB served as an index for measuring positive organisational change.

Motivation for the study: Little empirical research has investigated the application of positive organisational behaviour to government organisations undergoing organisational change. Organisations can use the study results to increase positive outcomes and reduce resistance in government organisations experiencing a holistic change intervention.

Research design, approach and method: The data comprised a cross-sectional survey of 97 employees from a government organisation that provides life-cycle career management support. Employees completed the 24-item psychological capital questionnaire, the 16-item organisational citizenship behaviour scale and the 17-item resistance to change scale. Data analyses used a mixed methods approach to merge quantitative inferential statistics with qualitative thematic analysis.

Main findings: The quantitative analysis yielded high levels of resistance to change that moderated the positive effect of PsyCap on organisational citizenship behaviour. The thematic analysis revealed that affective, behavioural and cognitive forms of resistance to change were prevalent.

Practical/managerial implications: Organisational leaders should seek to reduce resistance and increase the resources that organisations need to effect positive organisational change.

Contribution/value-add: This study adds to the growing body of knowledge about positive organisational behaviour in government organisations.

\section{Introduction}

In the past decade, interest has focused on positive organisational scholarship (POS) and positive-orientated research in organisations (Youssef \& Luthans, 2012). Positive organisational scholarship is 'the examination of factors that enable positive consequences for individuals, groups, and organisations' (Cameron, Dutton \& Quinn, 2003, p. 5). One area of study that has applied POS is positive organisational behaviour. This refers to 'positively oriented human resource strengths and psychological capacities that can be measured, developed, and effectively managed for performance in today's workplace' (Luthans \& Church, 2002, p. 59).

Positive organisational scholarship has evolved since 2003. However, little empirical research has investigated the application of positive organisational behaviour in the context of government organisations involved in organisational change. Organisational change involves motivating employees in organisations to change their behaviours in new and unique ways (Armenakis \& Bedeian, 1999). Failure to understand the behaviours that result from change initiatives has led to increased costs and wasted resources when workers reject organisational change (Palmer, Dunford \& Akin, 2009).

\section{Purpose of the research}

With this study, the authors aimed to build on the positive organisational behaviour body of knowledge and examine positive psychological capital (PsyCap) in a government organisation that was undergoing comprehensive organisational change. 
Psychological capital is a construct that enables positive work-related outcomes and positive organisational change that are beneficial to organisations, like organisational citizenship behaviour (OCB) (Luthans, Youssef \& Avolio, 2007; Organ, 1988). When OCBs are positively orientated towards organisations, PsyCap may be their likely precursor (Fredrickson, 2003). Therefore, the study also aimed to extend previous research that concentrated on the antecedents and predictors of OCB (see Shahnawaz \& Jafri, 2009) and investigated PsyCap as a positive predictor of OCB in a government organisation. Because employee resistance to change (RTC) is a key barrier to organisational change (Armenakis \& Bedeian, 1999; Strebel, 1996), the authors investigated the role that RTC plays in moderating positive organisational change processes.

The article begins with a brief literature review of the theoretical framework and research hypotheses. The authors then present methods and results. They conclude with a discussion of significant findings, practical implications for organisational leaders, limitations of the study and recommendations for future research.

\section{Literature review}

\section{Organisational change}

Organisational change involves applying strategies from the behavioural sciences that aim at the planned change of the organisational work setting for improving organisational performance by modifying employee behaviours (Porras \& Robertson, 1992).

Major areas of change initiatives in organisations' internal environments include process-orientated, people-centred and structural changes (Weick \& Quinn, 1999). Processorientated changes relate to workflow and productivity as well as to changes in organisational processes, methods and procedures. In addition, process-orientated changes include production processes and how organisations create, organise or disseminate products or services at any organisational level (team, branch or division). People-centred change is change that affects employee attitudes, behaviours, skills or performance. People-centred changes address how employees learn new behaviours and skills. This type of change is concerned with how to think more than with what to think. Finally, structural change is change that addresses how organisations operate as well as the relationships between various working parts or elements within organisations. Structural changes involve the hierarchy of administrative procedures and management systems.

\section{Positive psychological capital}

Organisations, which are involved in organisational change, study and manage their positive psychological resource capacities (Avey, Wernsing \& Luthans, 2008; Larson \& Luthans, 2006; Youssef \& Luthans, 2007). In order for researchers to use capacities as predictor variables for organisational outcomes, the capacities must be:
1. positive

2. valid measures with extensive theory and research foundations

3. state-like (as opposed to trait-like)

4. researched, measured, developed and managed at the individual, micro level. (Luthans, 2002)

Certain resource capacities have been combined to form PsyCap (Luthans \& Youssef, 2004; Luthans, Luthans, \& Luthans, 2004). PsyCap refers to a person's positive psychological state of development. Self-efficacy to succeed at challenging tasks, optimism to succeed now and in the future, hope that goals will succeed and sustained resilience to succeed in the face of adversity characterise PsyCap (Luthans et al., 2007). Earlier studies have shown that the four PsyCap dimensions are conceptually independent (Luthans \& Jensen, 2002; Luthans, Avolio, Avey \& Norman, 2007; Snyder, Rand \& Sigmon, 2002) and empirically valid (Bryant \& Cvengros, 2004; Carifio \& Rhodes, 2002; Magaletta \& Oliver, 1999).

Whilst scholars and practitioners have given PsyCap less attention compared to other forms of capital, like human and social capital, research supports its development and management in organisations to increase organisational efficiency, productivity and the successful implementation of organisational change (Luthans et al., 2004). Empirical studies on PsyCap have explored its role in for-profit organisations and researchers should investigate the role of PsyCap in other organisational contexts, like nonprofit organisations, hospitals, education institutions and government organisations (Youssef \& Luthans, 2012).

\section{Organisational citizenship behaviour}

Organisational citizenship behaviour is a theoretical construct that measures unique types of individual discretionary work behaviour that benefits organisations (Organ, 1988). Organisational citizenship behaviour refers to behaviour that facilitates the maintenance and enhancement of the social and psychological context that supports task performance' (Organ, 1997, p. 91). Organisational citizenship behaviour comprises two factors (Lee \& Allen, 2002). Organisational citizenship behaviour towards individuals (OCBI) are behaviours directed toward people. They comprise altruism and courtesy. Organisational citizenship behaviour towards organisations (OCBO) are behaviours directed toward organisations. They comprise conscientiousness, sportsmanship and virtue. Prior research has used OCB as an indicator of employees' behavioural disposition toward positive organisational behaviour (Avey et al., 2008; Norman, Avey, Nimnicht \& Pigeon, 2010; Zhong, 2007). In this study, the authors used OCB as the index of positive organisational behaviour that enables change and facilitates the effective and efficient functioning of organisations.

\section{Resistance to change}

Research has reported that the employees who participate in organisational change sometimes meet the implementation of strategic change with RTC (Lines, 2004). Resistance to change 
is a construct that comprises the affective, intentional and cognitive domains of resistance. They describe behaviours that resist change and try to maintain the status quo (Szabla, 2007).

Affective resistance refers to the emotional response employees experience about change. Affective resistance amongst organisational employees is resistance in terms of feelings about change (anger or anxiety). Affective resistance is negative energy or the indication of fear, anger, sadness, surprise, disgust and contempt about change. Intentional resistance refers to the plan or action employees take because of the situation. Intentional resistance is also the intention to act in response to change, like complaining about change or trying to convince others to avoid change. Finally, cognitive resistance includes attitudes and beliefs about the positive or negative evaluation of resistance. Cognitive resistance involves thoughts about the necessity and benefit of organisational change.

The need to understand the effect of resistance has increased significantly in private industries and government organisations over the last decade because of globalisation, fast-changing markets and economic developments (Piderit, 2000). Because RTC can threaten and undermine organisational change, one important implication of RTC is its significant effect on employees' organisational commitment, job-satisfaction and intention to leave their organisations (Oreg, 2006; Van den Heuvel \& Schalk, 2009). Therefore, organisations that evaluate RTC may provide an important point of reference to understand the variables that support organisational change through positive organisational behaviour better (Del Val \& Fuentes, 2003).

\section{Study model}

This study investigated PsyCap, OCB and RTC amongst employees of a government organisation that provides personnel and career management support. During the timeframe of this study, the organisation was in the process of comprehensive organisational change it designed to increase effectiveness and efficiency throughout its business processes.

The authors tested two research hypotheses about the relationship between PsyCap, RTC and OCB (see Figure 1). In both hypotheses, the authors inferred positive organisational behaviour from increases in OCB. The authors evaluated the role of PsyCap in promoting OCB in the first hypothesis and the role of RTC in moderating the effect of PsyCap on OCB in the second one.

Hypothesis 1: Psychological capital has a positive relationship with organisational citizenship behaviour.

Hypothesis 2: Resistance to change moderates the positive relationship between psychological capital and organisational citizenship behaviour.

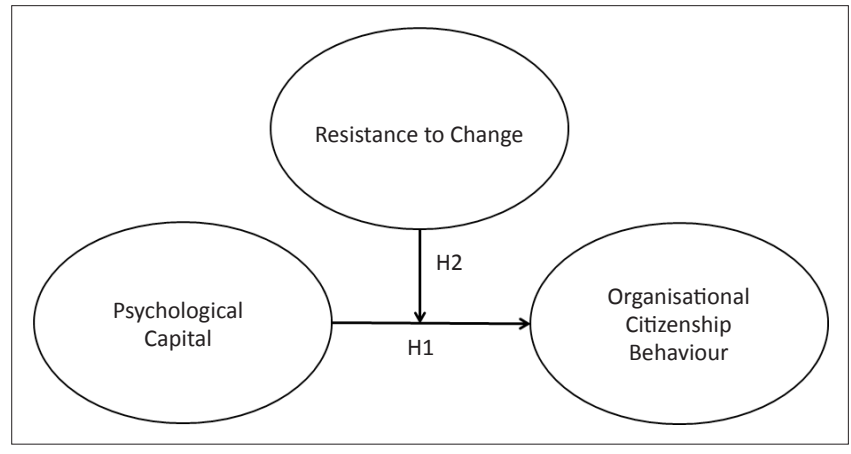

FIGURE 1: The theoretical framework and model.

\section{Research design}

Research approach

The study data comprised cross-sectional survey data that the authors analysed using a mixed methods approach so that they merged quantitative inferential statistics with qualitative thematic analysis.

The results of the study have implications for practice and research in the areas of positive resource capacities and resistance amongst governmental employees during organisational change.

\section{Research method}

The authors discuss the research method under four subheadings.

\section{Research participants}

The research participants comprised 400 employees at a government organisation that provides life-cycle career management support.

Fewer than six months before the study, the organisation had completed a relocation and organisational change that involved a movement from one location to another, organisational redesigns, changes in employee roles and modification of information systems technologies.

The authors conducted power analysis to estimate a target sample size for the study (Faul, Erdfelder, Buchner \& Lang, 2009). Therefore, the authors recruited a sample of 100 employees to be study participants.

Table 1 shows that the final study sample of 97 employees comprised 60 males and 37 females aged between 18 and 60 . Approximately half were between 41 and 50 years old. The organisation had employed most participants (84\%) for fewer than two years. The rest had worked between three and 10 years (10\%), between 11 and 20 years (3\%) and between 21 and 40 years (3\%). Approximately $24 \%$ of the employees had supervisory roles whilst $76 \%$ had non-supervisory roles.

\section{Measuring instruments}

The authors administered an online survey that comprised three quantitative instruments that they used to measure 
TABLE 1: Demographic characteristics of the participants $(N=97)$.

\begin{tabular}{lll}
\hline Demographic characteristics & $N$ & $\%$ \\
\hline Gender & 60 & $61.9^{*}$ \\
Male & 37 & 38.1 \\
Female & & \\
Age & 4 & $4.1^{*}$ \\
18-28 years & 36 & 37.1 \\
29-40 years & 44 & 45.4 \\
$41-50$ years & 14 & 13.4 \\
$51-60$ years & & \\
Years of employment & 81 & $83.5^{*}$ \\
$0-2$ years & 10 & 10.3 \\
3-10 years & 3 & 3.0 \\
$11-20$ years & 3 & 3.0 \\
21-40 years & &
\end{tabular}

Frequency is a percentage of the total $(N=97)$.

Chi-square test for equality of distribution.

Chi-square
$*, p<0.05$.

self-reported PsyCap, RTC and OCB to the employees. The authors scored each item of the three quantitative measures along the same six-point Likert-type scale that ranged from $1=$ strongly disagree to $6=$ strongly agree .

The survey also contained demographic and qualitative items. The demographic items comprised gender ( $1=$ male; 2 = female), age $(1=18-28$ years; $2=29-40$ years; $3=41-50$ years and $4=51-60$ years $)$ and years of employment $(1=0-2$ years; $2=3-10$ years; $3=11-20$ years and $4=21-40$ years).

Three open-ended questions captured the qualitative data:

- Question 1 (Q1) read 'Positive organisational change occurs when an organisation is altered to improve efficiency and effectiveness. Please describe positive organisational change in your organisation'

- Question 2 (Q2) read 'Describe a time when you felt positive about job related changes. How did you facilitate change?'

- Question 3 (Q3) read 'Employee resistance may have a negative impact on implementing organisational change. Resistance comes in many forms, from cynicism to rejection of proposed changes. Describe an instance in which you or a co-worker observed or exhibited resistant behaviour'.

The psychological capital questionnaire (PCQ): The authors used the 24-item PCQ to measure PsyCap (Luthans et al., 2007). The PCQ has demonstrated adequate psychometric properties in several samples (Avey et al., 2009; Luthans et al., 2007; Luthans, Avey, Clapp-Smith \& Li, 2008). In addition to a composite full-scale construct, the PCQ measured four subscale constructs: hope (6 items), optimism (6 items), resiliency (6 items) and self-efficacy (6 items). The authors used the full-scale score as the measure of PsyCap.

In the study sample, the PCQ showed strong internal consistency reliability for the full scale $(\alpha=0.91)$ and the four subscales (hope, $\alpha=0.86$; optimism, $\alpha=0.72$; resiliency, $\alpha=0.80$; self-efficacy, $\alpha=0.88$ ). The PCQ also showed acceptable construct validity as evaluated via second-order confirmatory factor analysis (CFA) under full information maximum likelihood estimation (FIML). The overall model fit was $\chi^{2}=393.90 ; d f=243 ; p<0.01$; RMSEA $(90 \% \mathrm{CI})=0.08$ $(0.07-0.10)$; and CFI $=0.88$. These goodness-of-fit tests were acceptable using criteria that Bentler (2007) established: ratio of the chi-square statistic to the degrees of freedom $\left(\chi^{2} / d f\right)$ less than 2-to-1, CFI value $\geq 0.80$ and RMSEA $\leq 0.08$.

The organisational citizenship behaviour scale: The authors measured OCB using the 16-item OCB scale (Lee, \& Allen, 2002). It is a composite of two subscales: an eight-item scale directed towards individuals (OCBI) and an eight-item scale directed towards the organisation (OCBO). The authors used the composite full-scale OCB score as the index of positive organisational behaviour.

The OCB full scale showed strong internal consistency reliability in the study $(\alpha=0.95)$. The authors also found strong internal consistency reliability for the two subscales (OCBI $\alpha=0.91$ and OCBO $\alpha=0.92$ ). The construct validity of the OCB scale, according to second-order CFA, was acceptable according to the following goodness-of-fit tests: $\chi^{2}=171.82 ; d f=98 ; p<0.01 ;$ RMSEA $(90 \% \mathrm{CI})=0.08$ (0.07-0.11); CFI = 0.94.

The resistance to change scale: The authors measured RTC using the 17-item RTC scale (Oreg, 2006). In addition to a composite full-scale RTC construct, the RTC scale provides four subscale scores: routine seeking (five items), emotional reaction to imposed change (four items), short-term focus (four items) and cognitive rigidity (four items). The authors used the composite RTC full-scale score as the measure of resistance to change.

The RTC scale showed strong internal consistency reliability for the full scale $(\alpha=0.89)$ and the four subscales (routine seeking, $\alpha=0.78$; emotional reaction, $\alpha=0.94$; short-term focus, $\alpha=0.93$; and cognitive rigidity, $\alpha=0.65$ ). The RTC scale also showed acceptable construct validity as evaluated via second-order CFA. The overall model fit was $\chi^{2}=162.94$; $d f=114 ; p<0.01 ;$ RMSEA $(90 \% \mathrm{CI})=0.07(0.04-0.09)$; and $\mathrm{CFI}=0.93$.

\section{Research procedure}

The research procedure of the study involved inviting employees to serve as research participants by completing an electronic survey administered via the SurveyMonkey ${ }^{\mathrm{TM}}$ internet-based survey interface. Page one of the survey contained the informed consent form. It informed participants that participation in the study was voluntary and that they were free to withdraw at any time. The authors protected the confidentiality of research participants according to the ethical guidelines that the Institutional Review Board has established. The study began with a pilot phase to test the survey and determine if any changes were necessary. The first ten participants served as the pilot sample. 
TABLE 2: Intercorrelations between study variables $(N=97)$.

\begin{tabular}{|c|c|c|c|c|c|c|c|}
\hline Variable & $M$ & SD & 1 & 2 & 3 & 4 & 5 \\
\hline 1. Gender & 1.38 & 0.49 & - & - & - & - & - \\
\hline 2. Age & 2.68 & 0.76 & $-0.32 * *$ & - & - & - & - \\
\hline 3. Years of employment & 1.26 & 0.67 & 0.08 & $0.23 *$ & - & - & - \\
\hline 4. Positive psychological capital & 4.99 & 0.52 & 0.15 & $-0.24 *$ & -0.20 & - & - \\
\hline 5. Organisational citizenship behaviour & 5.17 & 0.64 & 0.02 & -0.11 & $-0.25 *$ & $0.62 * *$ & - \\
\hline 6. Resistance to change & 3.00 & 0.62 & $-0.23 *$ & 0.11 & -0.01 & $-0.36 * *$ & $-0.40 * *$ \\
\hline
\end{tabular}

Pearson's correlation coefficient.

$*, p<0.05 ; * *, p<0.01$.

\section{Data analysis}

The authors analysed the quantitative data using descriptive and inferential statistics via Minitab 16 and Mplus6. The inferential statistics comprised the chi-square test of sample distribution, reliability analysis, confirmatory factor analysis, Pearson correlations, analysis of variance (ANOVA) as well as general and stepwise multiple regression models. The authors transcribed the qualitative data into Microsoft Excel ${ }^{\mathbb{R}}$ and analysed and coded them using thematic analysis.

A theme is a cluster of linked categories that convey similar meanings. For the thematic analysis, the authors generated themes using a deductive, top-down method for analysing qualitative data, as Boyatzis (1998) prescribed.

\section{Results}

\section{Quantitative analysis}

Table 2 presents the means, standard deviations and bivariate correlations of the study variables. It shows that PsyCap and RTC were both related to the study outcome variable OCB, with PsyCap positively correlated $(r=0.62 ; p<0.01)$ and RTC negatively correlated $(r=-0.40 ; p<0.01)$. RTC also had a negative correlation with PsyCap $(r=-0.36 ; p<0.01)$.

The strong positive correlation between PsyCap and OCB supports Hypothesis 1 that PsyCap has a positive relationship with OCB. Therefore, employees who report high PsyCap are likely to report high OCB. The negative correlations between RTC and PsyCap, and between RTC and OCB, suggest that employees who report high levels of RTC are likely to report low levels of PsyCap and OCB.

The authors used hierarchical regression to evaluate the second study hypothesis that RTC moderates the positive relationship between PsyCap and OCB.

In step 1 of the regression, the authors entered the demographic variables of gender, age and years of employment as covariates to characterise their contribution to the total variance in OCB. Table 3 shows that these covariates accounted for a small portion of the variance in OCB $(R$-square $=0.07)$.

In step 2, the authors entered the predictor PsyCap into the regression. In continued support of hypothesis 1 , the authors found that PsyCap was a significant predictor of OCB $(\beta=0.76 ; p<0.01)$ and accounted for $40 \%$ of the variance in
TABLE 3: Hierarchical regression of organisational citizenship behaviour regressed on positive psychological capital and resistance to change $(N=97)$. Variable Organisational citizenship behaviour

\begin{tabular}{lcccc} 
& Step 1 & Step 2 & Step 3 & Step 4 \\
\hline Gender & 0.03 & 0.06 & 0.01 & 0.05 \\
Age & -0.05 & 0.08 & 0.07 & 0.06 \\
Years of employment & $-0.27^{*}$ & -0.12 & -0.13 & -0.13 \\
Positive psychological capital (PsyCap) & - & $0.76^{* *}$ & $0.66^{* *}$ & $0.64^{* *}$ \\
Resistance to change (RTC) & - & - & $-0.23^{*}$ & $-0.22^{*}$ \\
Interaction term (PsyCap x RTC) & - & - & - & $.11^{*}$ \\
Total $R$-square & 0.07 & 0.40 & 0.44 & 0.48 \\
Change in $R$-square & - & $0.33^{* *}$ & $0.04^{*}$ & $0.04 *$ \\
\hline
\end{tabular}

Regression coefficient, Change in $R$-square. $*, p<0.05 ;{ }^{* *}, p<0.01$.

OCB $\left(R^{2}=0.40\right)$. The change in $R$-square from Step 1 to step 2 was significant at the 0.01 level.

In step 3 , the authors found a significant negative relationship between RTC and OCB $(\beta=-0.23 ; p<0.05)$. The change in $R$-square from step 2 to step 3 was significant at the 0.05 level.

Finally, the authors entered the interaction term of PsyCap $x$ RTC in step 4 of the regression. They found that the interaction term was significant $(\beta=0.11 ; p<0.05)$, with the full set of predictors $(R$-square $=0.48)$, accounting for almost half of the variance in OCB. The change in $R$-square from step 3 to step 4 was significant at the 0.05 level. Taken together, these results support Hypothesis 2 that RTC moderates the relationship between PsyCap and OCB.

To facilitate the interpretation of the significant interaction term in step 4 of the regression, the authors plotted OCB as a function of the main and interactive effects of PsyCap and RTC (see Figure 2). Employees who reported low resistance were likely to report high OCB when their PsyCap was in the range of moderately low to high (i.e., responses in the range of 'somewhat disagree' to 'strongly agree'). On the other hand, employees who reported high resistance were likely to report high OCB when PsyCap was high (i.e., responses in the range of 'somewhat agree' to 'strongly agree').

\section{Qualitative analysis}

The thematic analysis identified three themes related to organisational change and three themes related to resistance to change. The authors sorted the qualitative responses to open-ended questions Q1 and Q2 into three themes related to the major areas of organisational change initiatives (Weick \& Quinn, 1999): process-orientated change, people-centred 


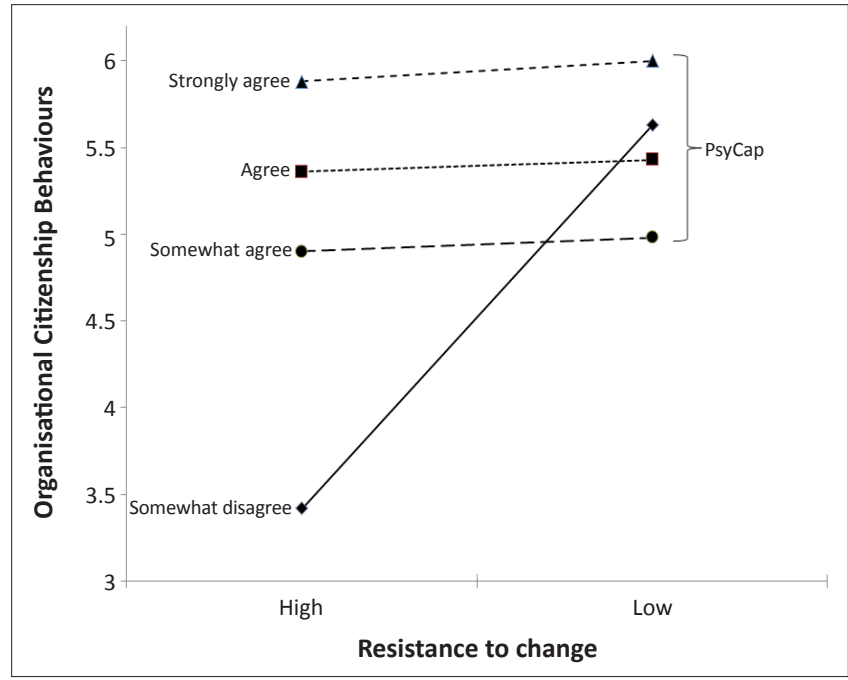

FIGURE 2: Resistance to change moderating the positive effect of positive psychological capital on organisational citizenship behaviours.

change and structural change. They sorted the responses to open-ended question Q3 into three themes related to the multidimensional nature of resistance that the employees observed or experienced (Szabla, 2007): affective resistance, intentional resistance and cognitive resistance.

\section{Process-orientated change}

The following three responses exemplify process-orientated change:

'There was a change in the way to process school payments and the use of electronic process instead of paper.' (41-50 years of age, male, $0-2$ years employed)

'By researching current policies and procedures I was able to identify some areas that were ambiguous. Clarifying these areas allowed the organisation to alter the approval/disapproval authority and process vice doing things 'the way we have been.' (41-50 years of age, male, $0-2$ years employed)

'The Lean 6 Sigma mapping has been rewarding. We identified processes, but have made several recommendations to processes. I anticipate many changes will be made due to the fact that inefficiencies have been identified.' (29-40 years of age, male, $0-2$ years employed)

There were twice as many responses that indicated peoplecentred or structural change than there were responses that indicated process-orientated change. Employees indicated that they felt more positive toward process-orientated change than change related to individual attitudes, behaviours, skills or performance (i.e., people-orientated change). Therefore, employees appeared to be more accustomed to processorientated change than to other forms of organisational change.

\section{People-centred change}

The following three responses exemplify people-centred change:

'I usually feel positive about most changes; cannot recall a specific time. Change is usually for the better, so I try to support any change and always try to think of more efficient and effective ways to do my job.' (29-40 years of age, female, 0-2 years employed)
'The willingness of new personnel to work together as a cohesive team.' (41-50 years of age, male, 3-10 years employed)

'I've noticed co-workers working together and sharing knowledge in learning new computer software.' (41-50 years of age, female, $0-2$ years employed)

Qualitative responses that indicated people-centred change accounted for approximately $20 \%$ of all responses related to organisational change. People-centred change addressed how employees reacted to change, learned new skills and perceived themselves in their new organisational roles.

\section{Structural change}

The following three responses exemplify structural change:

'The organisation recently re-aligned some of the functions and responsibilities in order to streamline the hiring and orders process.' (29-40 years of age, male, $0-2$ years employed)

'The consolidation of management ... is beginning to result in a more controlled use of human resources resulting in increased efficiencies.' (41-50 years of age, male, 0-2 years employed)

'Section reorganizing/moving personnel to locations will provide improved communication and production within sections.' (51-60 years of age, male, $0-2$ years employed)

Qualitative responses that indicated structural change had the fewest number of responses. Structural change addressed allocation of responsibilities to different work activities. Other structural change examples included the increase in the number of employees in some sections, realignment of work tasks and changes in the structure of key leaders within the organisation.

\section{Affective resistance}

The following three responses exemplify affective resistance:

'Some officers were not excited to participate in the Lean 6 Sigma process.' (29-40 years of age, male, $0-2$ years employed)

'Proponents of different parts of the process were resistant because they felt they would lose some form of control over the process. They resisted by not answering emails/phone calls, responding with opinions instead of regulatory guidance and seeking outside intervention from other influential people.' (2940 years of age, female, $0-2$ years employed)

'When new processes are not shared, explained, or taught, then the urge to change has been less than favourable.' (29-40 years of age, male, 0-2 years employed)

Approximately one-third of qualitative responses related to resistance identified affective resistance. Employees reported affective resistance in terms of negative feelings through facial and bodily changes as well as a lack of enthusiasm about organisational change.

\section{Intentional resistance}

The following three responses exemplify intentional resistance:

'I observed resistant behaviour when my co-workers complain about being overworked and when no one wants to go the extra mile to accomplish tasks.' (29-40 years of age, male, $0-2$ years employed) 
'I see co-workers who complained and resist work that, I believe, they should execute. Also, I see resistance of some leaders who do not follow the rules, e.g. my chief and division chief sometimes ignore guidance from command branch.' (29-40 years of age, male, 0-2 years employed)

'I observed resistance to change with the change to a paperless culture. The "old timers" had and still have a hard time adjusting. Some are not as tech savvy as a lot of the younger workers and would rather do things the old-fashioned way by using hard copies. They complain and some still continue to print everything off.' (29-40 years of age, female, 0-2 years employed)

Approximately one-third of qualitative responses about resistance identified intentional resistance in the form of complaints and intention to avoid change.

\section{Cognitive resistance}

The following three responses exemplify cognitive resistance:

'Many employees resisted changes on 'the way it was always done', from big things to little things - how a document is formatted, or how a slide is briefed.' (29-40 years of age, male, 0-2 years employed)

'The repeated lack of willingness to understand processes on the part of leadership can cause conflict within the organisation, resulting in barriers to development of more efficient processes.' (41-50 years of age, male, $0-2$ years employed)

'Resistance is across the board with the new Web management tool. Though when operational the new tool seems to be more efficient and easier to use, it appears as if most web managers are resistant to the change calling it unnecessary. At least that's the feedback I got while in the training for the new web tool.' (29-40 years of age, male, 0-2 years employed)

The authors classified approximately one-third of employees' responses related to resistance as cognitive resistance in terms of thoughts and perceptions of resistance.

\section{Discussion}

The authors aimed to contribute to the research on positive organisational behaviour by investigating positive psychological capital, organisational citizenship behaviour and resistance to change in a government organisation during its business transformation.

The quantitative analysis of the data from 97 employees showed that PsyCap had a positive relationship with OCB. Results also showed that RTC moderated the effect of PsyCap on OCB. Employees who reported high resistance reported low levels of PsyCap OCB.

The quantitative results support extant theories of PsyCap as a precursor to OCB (Avey et al., 2008; Norman et al., 2010; Zhong, 2007) and suggest that PsyCap plays an important role in facilitating organisational change through the effective and efficient functioning of the organisational system. By testing PsyCap as a predictor of OCB, the study supports previous research that focused on identifying antecedents of OCB (see Shahnawaz \& Jafri, 2009).
The qualitative data added to the hypothesis testing by generating themes on process-orientated, people-centred and structural areas of organisational change (Weick \& Quinn, 1999) as well as themes on affective, intentional and cognitive dimensions of resistance (Szable, 2007). With regard to organisational change, the finding that process-orientated change accounted for most employee open-ended responses on change is important because of the potential positive effect of business transformation to increase efficiency and employee effectiveness by improving processes.

For example, government organisations have recently received guidance on conducting Lean and Six Sigma process improvement initiatives (Schoomaker \& Harvey, 2005). With regard to qualitative responses related to resistance, the finding that the open-ended responses distributed equally across the affective, intentional and cognitive dimensions of resistance indicates that all forms of resistance were equally prevalent.

The qualitative data support social exchange theory as a theoretical pathway through which PsyCap influences positive organisational change. Social exchange theory is the result of an exchange process, the purpose of which is to maximise benefits and reduce costs until risks outweigh rewards (Cook \& Rice, 2003). Research suggests that social exchange theory is the catalyst between family-friendly environments and positive job-related attitudes (Sahibzada, Hammer, Neal \& Kuang, 2005; Sinclair, Hannigan \& Tetrick, 1995). One can extend social exchange theory to positive organisational behaviour in that, taken together, citizenship behaviours improve group performance because they help people to work together (Organ, 1988; Podsakoff, Ahearne \& MacKenzie, 1997).

Given the behavioural properties and the relationship between PsyCap and OCB, employees in this study may have engaged in a social exchange in which PsyCap led to greater efficiency in organisational change (see Figure 3).

The qualitative data also support the relationship between positivity and broader thought-action repertoires and further explain the link between PsyCap and organisational change. For example, broaden-and-build theory states that positive emotions and orientations broaden people's attention and helps to focus their thinking and behavioural repertoires (Fredrickson, 2001). The study supports the

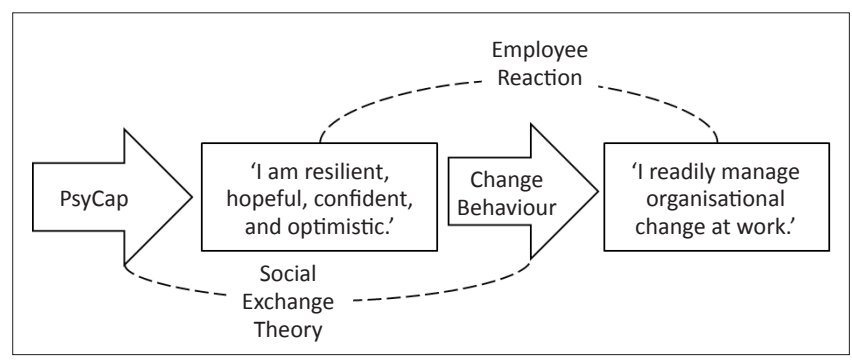

FIGURE 3: The social exchange theory at work in the organisation. 
broaden-and-build theory empirically in that it found that broader behaviours had relationships with OCB in terms of conscientious and virtuous behaviours directed toward the organisation. For example, the qualitative data suggests that employees displayed various virtuous behaviours that one would not normally consider part of their job descriptions, like sharing or assisting with ideas and suggestions.

The quantitative results showed a significant interaction between PsyCap and RTC in multiple regression analysis and the thematic analysis identified potential sources of resistance.

The authors mixed these two points of reference to develop a force field diagram, based on Kurt Lewin's classic force field analysis technique (Lewin, 1943). It illustrates the drivers of, and resisters to, organisational change (see Figure 4). Force field analysis provides a framework for looking at the primary factors of positive organisational behaviour that influence organisational change in terms of PsyCap (change enabling forces) and resistance (change hindering forces).

For example, optimism leads to a positive orientation towards change, self-efficacy builds confidence and reduces fear of change, resilience increases an employee's ability to adapt to and overcome change and a hopeful employee will find a way to deal with change. These positive behaviours push against resistant change behaviours, like behavioural reluctance about new technologies and processes, lack of teamwork because of a 'what's in it for me' mentality and cynicism about change.

\section{Managerial implications and recommendations}

Luthans and Youssef (2004) posited that 'There is growing evidence that human resources are crucial to organisational success, and may offer the best return on investment for sustainable competitive advantage' (p. 144). Specifically, human resources benefit from the development of PsyCap, which is an extension of economic, human and social capital. Luthans et al. $(2004,2007)$ suggest that an organisation can increase its competitive advantage by developing and managing PsyCap amongst its employees.

The government organisation in the study underwent planned change in order to become more competitive. The results advance existing knowledge about the positive predictive relationship between PsyCap and positive organisational change. This predictive relationship provides a benchmark for understanding positive behaviour amongst employees. Researchers can use it for subsequent behavioural research or as part of change management applications.

This study builds on previous research that examined the relationship between, and importance of, positive employees and positive organisational change (see Avey et al., 2008). Understanding the role of positive behaviours in organisations can give leaders additional means of increasing employee efficiency and effectiveness.

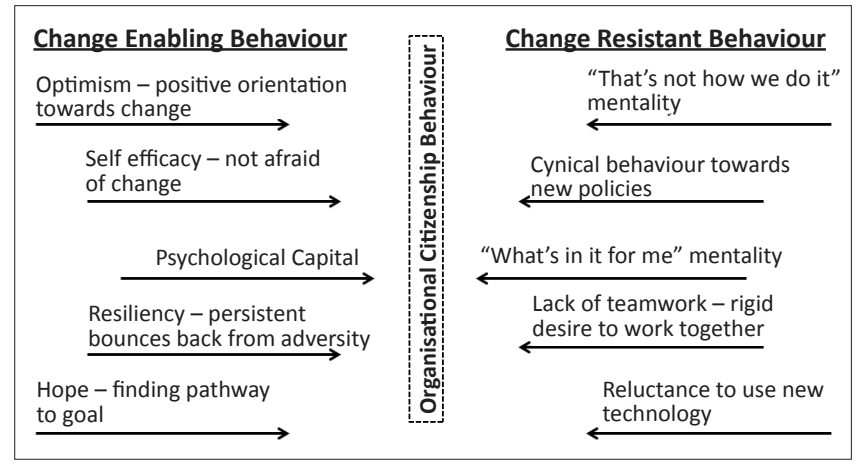

FIGURE 4: Drivers of, and resisters to, change in organisations.

Specifically, the authors recommend that organisations:

1. maximise the role of positive behaviour in organisational change;

2. focus on people-centred change to reduce resistance; and

3. manage PsyCap through actively educating and training employees on the role of PsyCap in the workplace.

Managing and increasing the level of PsyCap in organisations requires deliberate interventions. For example, organisations can increase the level of PsyCap by using short training sessions of one to three hour micro interventions in which they measure PsyCap before and after the interventions (Luthans, Avey, Avolio, Norman, \& Combs, 2006).

In addition, organisations can increase PsyCap through SOAR (strengths, opportunities, aspirations and results), a strategic thinking framework that integrates whole system and strengths-based perspectives to create a strategic transformation process with a focus on creating sustainable value to achieve desired performance results (Stavros \& Wooten, 2012).

Organisations use SOAR to encourage their employees to work together to create a shared understanding of the status of the organisations and construct their futures through dialogue and commitment to action. Research confirms that using strengths-based interventions creates positive emotions with upward spirals toward optimal individual and organisational performance (Fredrickson, 2003). SOAR is an example of a newer organisation development practice that builds on the premise that organisations can use shared dialogue about systems' strengths and opportunities to shape preferred futures that allow for positive changes in strategies, structures, business models, systems and processes (Rothwell, Stavros \& Sullivan, 2010).

As an expected response to any change initiative, organisations often cite RTC as a primary reason for lack of organisational change (Palmer et al., 2009; Stanley, Meyer \& Topolnytsky, 2005).

The thematic analysis found that affective, intentional and cognitive forms of resistance were prevalent amongst employees. Therefore, it is feasible that these forms of resistance contributed to the moderation of the PsyCapOCB relationship. The thematic analysis also highlights the 
implications for the negative effect of resistance on positive organisational change: reduced morale, decreased efficiency and disruptive work environments (Laframboise, Nelson, \& Schmaltz, 2003).

Resistance to change lowers morale by reducing optimism and hope, which are catalysts for positive organisational change. Resistance to change also decreases employee efficiency because employees are distracted from completing their daily tasks.

Finally, employees with high RTC express negativity and resistance that may contribute to disruptive work environments.

\section{Limitations of the study}

There are at least four methodological limitations of the study.

Firstly, using a cross-sectional design limits the inference of causal relationships. Specifically, by not using experimental manipulation, random assignment or longitudinal analysis, the authors could not infer causal effects between PsyCap, OCB and RTC.

A second limitation concerns the theorised relationship between PsyCap and OCB. Specifically, the study did not address other variables that may affect the relationship between PsyCap and OCB. For example, it should have considered intervening variables like subordinates' work effort or management teams' performance that could play roles in the PsyCap-OCB relationship.

The study examined the effects of PsyCap on OCB in the context of only one organisation, and a limitation concerns generalising results to other organisations. For example, in a comparative study that explored the role of PsyCap in Indian public and private organisations, Shahnawaz and Jafri (2009) reported that regression analyses did not find that PsyCap was a significant predictor of OCB. Therefore, although the results of the current study are consistent with studies that have identified a link between PsyCap and OCB (see Avey, et al., 2008; Luthans, Avolio, Walumbwa \& Li, 2005; Norman, Avey, Nimnicht \& Piegeon, 2009), the extent to which these results generalise to other organisations or industries is unknown.

A final limitation the authors noted is common source bias, in which researchers use the same sample to gather data on both independent and dependent variables. This method of obtaining data may result in common source bias and lead to inflated relationships (Podsakoff, MacKenzie, Lee \& Podskoff, 2003). The prescribed approach to reducing common source bias is to obtain predictor measurements from one observer and measurements of outcomes from another (or use separate occasions for measuring). The authors did not use these methods because of resource constraints about the ability to issue several surveys and use several observers. However, one should note that data from distinct observers or measurement occasions might distort the prediction estimates as much as common source variance does (Kammeyer-Muller, Steel \& Rubenstein, 2010).

\section{Suggestions for future research}

The authors asked employees about their level of PsyCap and OCB as they related to their organisational change experiences. However, PsyCap and OCB were not associated with any specific change indicating metric, like the number of employees who embraced the use of a newly implemented automation system. Linking these two theoretical constructs to real world metrics would move research on PsyCap and OCB from theory to practice. In addition, context was a key factor in the study and future research should investigate the effect of PsyCap-OCB on organisational change by stratifying context further.

The qualitative results showed that the primary area of organisational change was process-orientated change. The thematic analysis showed that process-orientated change was nearly twice that of people-centred change and three times that of structural change. Study results may change if peoplecentred or structural change becomes prevalent. Therefore, future research should continue to use qualitative data, like data from focus groups, to investigate areas of organisational change at the team or business-unit level.

Finally, future research in the area of PsyCap would benefit from longitudinal studies in which researchers observe levels of PsyCap, OCB and RTC over time in the context of organisational change. The cross-sectional data the authors collected in the study provided a snap shot in time, limiting the understanding of how PsyCap, OCB and RTC interact overtime. A longitudinal study would yield this information. For example, a longitudinal study could measure the ability of PsyCap to predict OCB before, during and after a significant change event. In addition, researchers could determine the moderating role of RTC during these same periods. This would reveal the point in time that resistance has the greatest effect. This knowledge could inform change managers who wish to focus their efforts by increasing PsyCap and decreasing resistance at the most opportune time.

\section{Conclusion}

This study explored some of the positive aspects of human behaviour in a government organisation setting (Seligman \& Csikszentmihalyi, 2000). The theoretical foundation was positive organisational scholarship (POS) and the authors measured positive resource strengths and capacities in the form of PsyCap. The study examined the effect of PsyCap on OCB, where OCB served as an index for measuring positive organisational change (Luthans \& Church, 2002).

Positive behaviour does not occur in a vacuum, and researchers in the field of positive organisational behaviour have asked that research include examining moderators when determining the relationship between POS constructs 
(Luthans, 2002; Norman et al., 2010). Accordingly, the authors included RTC as a moderator of the relationship between PsyCap and OCB. Furthermore, this study took a balanced approach in that it focused on strengths but acknowledged weaknesses, like RTC, which is in the spirit of positive psychology (Cameron et al., 2003; Fineman, 2006).

As an empirical analysis of PsyCap in a government organisation that was undergoing a holistic change intervention, this study provides new information that organisations can use to increase positive outcomes and reduce resistance to organisational change. In addition to its practical applications, the study adds to the growing body of knowledge about positive organisational behaviour in two ways.

First, the authors found a positive relationship between PsyCap and OCB in the context of organisational change. Organisation leaders should increase positive organisational behaviour by managing PsyCap and its four positive psychological capacities (hope, optimism, self-efficacy and resilience). Secondly, the authors identified RTC as a moderator of PsyCap's effect on OCB. The results suggest that high levels of PsyCap can rise above the moderating effects of RTC. Consequently, organisation leaders should try to reduce resistance and increase the resources organisations need to effect positive organisational change.

\section{Acknowledgements Competing interests}

The authors declare that they have no financial or personal relationship(s) that may have inappropriately influenced them when they wrote this article.

\section{Authors' contributions}

This article uses the doctoral research L.B.III (Lawrence Technological University) as its basis. J.M.S. (Lawrence Technological University) and M.L.C. (Lawrence Technological University) respectively, also acted as supervisors for the study. J.M.S (Lawrence Technological University) was the chair and M.L.C. (Lawrence Technological University) was the statistical advisor. In these capacities, they were extensively involved in conceptualising and writing this article.

\section{References}

Armenakis, A.A., \& Bedeian, A.G. (1999). Organizational change: A review of theory and research in the 1990s. Journal of Management, 25, 293-315. http://dx.doi. org/10.1177/014920639902500303

Avey, J.B., Luthans, F., \& Jensen, S.M. (2009). Psychological capital: A positive resource for combating employee stress and turnover. Human Resource Management, 48(5), 677-693. http://dx.doi.org/10.1002/hrm.20294

Avey, J.B., Wernsing, T.S., \& Luthans, F. (2008). Can positive employees help positive organizational change? Impact of psychological capital and emotions on relevant attitudes and behaviours. Journal of Applied Behavioral Science, 44(1), 48-70. http://dx.doi.org/10.1177/0021886307311470

Bentler, P.M. (2007). On tests and indices for evaluating structural models. Personality and Individual Differences, 42(5), 825-829. http://dx.doi.org/10.1016/j. paid.2006.09.024
Boyatzis, R.E. (1998). Transforming qualitative information: Thematic analysis and code development. Thousand Oaks, CA: Sage Publications, Inc. PMid:9729839

Bryant, F.B., \& Cvengros, J.A. (2004). Distinguishing hope and optimism: Two sides of a coin, or two separate coins? Journal of Social and Clinical Psychology, 23(2), 273-302. http://dx.doi.org/10.1521/jscp.23.2.273.31018

Cameron, K.S., Dutton, J.E., \& Quinn, R.E. (2003). Positive organizational scholarship Foundations of a new discipline (1st edn.). San Francisco, CA: Berrett-Koehler.

Carifio, J., \& Rhodes, L. (2002). Construct validities and the empirical relationships between optimism, hope, self-efficacy, and locus of control. Work: Journal of Prevention, Assessment \& Rehabilitation, 19(2), 125-136.

Cook, K.S., \& Rice, E. (2003). Social exchange theory. In J. Delamater (Ed.), Handbook of social psychology (pp. 53-76). New York, NY: Kluwer Academic/Plenum Publishers. PMid:12906404

del Val, M.P., \& Fuentes, C.M. (2003). Resistance to change: A literature review and empirical study. Management Decision, 41(2), 148-155. http://dx.doi. org/10.1108/00251740310457597

Faul, F., Erdfelder, E., Buchner, A., \& Lang, A.-G. (2009). Statistical power analyses using G*Power 3.1: Tests for correlation and regression analyses. Behavior Research Methods, 41, 1149-1160. http://dx.doi.org/10.3758/BRM.41.4.1149

Fineman, S. (2006). On being positive: Concerns and counterpoints. The Academy of Management Review, 31(2), 270-291. http://dx.doi.org/10.5465/AMR.2006. 20208680

Fredrickson, B.L. (2001). The role of positive emotions in positive psychology: The broaden-and-build theory of positive emotions. American Psychologist, 56(3), 218-226. http://dx.doi.org/10.1037/0003-066X.56.3.218, PMid:11315248

Fredrickson, B.L. (2003). The value of positive emotions. American Scientist, 91, 330-335. http://dx.doi.org/10.1511/2003.26.865, http://dx.doi.org/10.1511/2003.4.330

Kammeyer-Muller, J., Steel, P.D.G., \& Rubenstein, A. (2010). The other side of method bias: The perils of distinct source research designs. Multivariate Behavioral Research, 45, 294-321. http://dx.doi.org/10.1080/00273171003680278

Laframboise, D., Nelson, R.L., \& Schmaltz, J. (2003). Managing resistance to change in workplace accommodation projects. Journal of Facilities Management, 1(4), 306. http://dx.doi.org/10.1108/14725960310808024

Larson, M., \& Luthans, F. (2006). Potential added value of psychological capital in predicting work attitudes. Journal of Leadership \& Organizational Studies, 13(1), 45-62. http://dx.doi.org/10.1177/10717919070130010701

Lee, K., \& Allen, N.J. (2002). Organizational citizenship behaviour measure. Journal of Applied Psychology, 87, 131-142. http://dx.doi.org/10.1037/0021-9010.87.1.131, PMid:11916207

Lewin, K. (1943). Defining the 'field at a given time'. Psychological Review, 50(3), 292 310. http://dx.doi.org/10.1037/h0062738

Lines, R. (2004). Influence of participation in strategic change: Resistance, organizational commitment and change goal achievement. Journal of Change Management, 4(3), 193-215. http://dx.doi.org/10.1080/1469701042000221696

Luthans, F. (2002). The need for and meaning of positive organizational behaviour. Journal of Organizational Behavior, 23(6), 695-706. http://dx.doi.org/10.1002/ job.165

Luthans, F., Avey, J.B., Avolio, B.J., Norman, S.M., \& Combs, G.M. (2006). Psychological capital development: Toward a micro-intervention. Journal of Organizational Behavior, 27(3), 387-393. http://dx.doi.org/10.1002/job.373

Luthans, F., Avey, J.B., Clapp-Smith, R., \& Li, W. (2008). More evidence on the value of Chinese workers' psychological capital: A potentially unlimited competitive resource? International Journal of Human Resource Management, 19(5), 818827. http://dx.doi.org/10.1080/09585190801991194

Luthans, F., Avolio, B.J., Avey, J.B., \& Norman, S.M. (2007). Positive psychological capital: Measurement and relationship with performance and satisfaction Personnel Psychology, 60(3), 541-572. http://dx.doi.org/10.1111/j.17446570.2007.00083.x

Luthans, F., Avolio, B. J., Walumbwa, F.O., \& Li, W. (2005). The psychological capital of Chinese workers: Exploring the relationship with performance. Management and Organization Review, 1(2), 249-271. http://dx.doi.org/10.1111/j.17408784.2005.00011.x

Luthans, F., \& Church, A.H. (2002). Positive organizational behaviour: Developing and managing psychological strengths. Academy of Management Executive, 16(1) 57-72. http://dx.doi.org/10.5465/AME.2002.6640181

Luthans, F., \& Jensen, S.M. (2002). Hope: A new positive strength for human resource development. Human Resource Development Review, 1(3), 304-322. http:// dx.doi.org/10.1177/1534484302013003

Luthans, F., Luthans, K. W., \& Luthans, B. C. (2004). Positive psychological capital: Beyond human and social capital. Business Horizons, 47(1), 45-50. http://dx.doi. org/10.1016/j.bushor.2003.11.007

Luthans, F., \& Youssef, C.M. (2004). Human, social, and now positive psychological capital management: Investing in people for competitive advantage. Organizational Dynamics, 33(2), 143-160. http://dx.doi.org/10.1016/j. Organizational Dynan
orgdyn.2004.01.003

uthans, F., Youssef, C.M., \& Avolio, B.J. (2007). Psychological capital: Developing the human competitive edge. New York, NY: Oxford University Press.

Magaletta, P.R., \& Oliver, J.M. (1999). The hope construct, will, and ways: Their relations with self-efficacy, optimism, and general well-being. Journal of Clinical Psychology, 55(5), 539-551. http://dx.doi.org/10.1002/(SICl)1097 4679(199905)55:5\%3C539::AID-JCLP2\%3E3.3.CO;2-7, http://dx.doi.org/10.1002/ (SICI) 1097-4679(199905)55:5\%3C539::AID-JCLP2\%3E3.0.CO;2-G 
Norman, S. M., Avey, J.B., Nimnicht, J. L., \& Pigeon, N. G. (2010). The interactive effects of psychological capital and organizational identity on employee organizational citizenship and deviance behaviours. Journal of Leadership \& Organizational citizenship and deviance behaviours. Journal of Leadership \& Organizd
Studies, 17(4), 380-391. http://dx.doi.org/10.1177/1548051809353764

Oreg, S. (2006). Personality, context, and resistance to organizational change. European Journal of Work and Organizational Psychology, 15(1), 73-101. http:// European Journal of Work and Organization
dx.doi.org/10.1080/13594320500451247

Organ, D.W. (1988). Organizational citizenship behaviour: The good soldier syndrome. Lexington, MA England: Lexington Books/D. C. Heath and Com.

Organ, D.W. (1997). Organizational citizenship behaviour: It's construct cleanup time. Human Performance, 10(2), 85-97. http://dx.doi.org/10.1207/ s15327043hup1002 2

Palmer, I., Dunford, R., \& Akin, G. (2009). Managing organizational change: A multiple perspectives approach (2nd edn.). New York, NY: McGraw-Hill.

Piderit, S. K. (2000). Rethinking resistance and recognizing ambivalence: A multidimensional view of attitudes toward an organizational change. Academy of Management Review, 25(4), 783-794. http://dx.doi.org/10.2307/259206, http:// dx.doi.org/10.5465/AMR.2000.3707722

Podsakoff, P.M., Ahearne, M., \& MacKenzie, S.B. (1997). Organizational citizenship behaviour and the quantity and quality of work group performance. Journa of Applied Psychology, 82(2), 262-270. http://dx.doi.org/10.1037/0021 9010.82.2.262, PMid:14516251

Podsakoff, P.M., MacKenzie, S.B., Lee, J.Y., \& Podsakoff, N.P. (2003). Common method biases in behavioural research: A critical review of the literature and recommended remedies. Journal of Applied Psychology, 88, 879-903.

Porras, J.I., \& Robertson, P.J. (1992). Organizational development: Theory, practice, research. In M.D. Dunnette \& L. M. Hough (Eds.), Handbook of organizationa psychology (2nd edn., pp. 719-822). Palo Alto, CA: Consulting Psychologists Press.

Rothwell, W.J., Stavros, J.S., \& Sullivan, R.L. (2010). Organization development and change. In W. J. Rothwell, J. S. Stavros, R. L. Sullivan \& A. Sullivan (Eds.), Practicing organization development: $A$ guide for leading change (3rd edn . pp. 11-42). San Francisco, CA: Pfeiffer.

Sahibzada, K., Hammer, L.B., Neal, M.B., \& Kuang, D.C. (2005). The moderating effects of work-family role combinations and work-family organizational culture on the relationship between family- friendly workplace supports and job satisfaction. Journal of Family Issues, 26(6), 820-839. http://dx doi. org/10.1177/0192513X05277546

Schoomaker, P.J., \& Harvey, F.J. (2005). Transforming the way we do business - Army lean six sigma deployment. Retrieved from http://dmna.ny.gov/plans_training/ $\mathrm{j} 5 /$ General\%20Interest/Other\%20Strategic\%20Docs/Continuous\%20Process\%20 Improvement/Army\%20LSS.pdf
Seligman, M.E.P., \& Csikszentmihalyi, M. (2000). Positive psychology: An introduction American Psychologist, 55(1), 5-14. http://dx.doi.org/10.1037/0003-066X.55.1.5, PMid:11392865

Shahnawaz, M.G., \& Jafri, M.H. (2009). Psychological capital as predictors of organizational commitment and organizational citizenship behaviour. Journal of the Indian Academy of Applied Psychology, 35, 78-84.

Sinclair, R.R., Hannigan, M.A., \& Tetrick, L.E. (1995). Benefit coverage and employee attitudes: A social exchange perspective. In L.E. Tetrick, \& J. Barling (Eds.), Changing employment relations: Behavioral and social perspectives (pp. 163-185). Washington, DC: American Psychological Association. http://dx.do org/10.1037/10185-008

Snyder, C.R., Rand, K.L., \& Sigmon, D.R. (2002). Hope theory: A member of the positive psychology family. In C.R. Snyder, \& S.J. Lopez (Eds.), Handbook of positive psychology (pp. 257-276). New York, NY: Oxford University Press.

Stanley, D.J., Meyer, J.P., \& Topolnytsky, L. (2005). Employee cynicism and resistance to organizational change. Journal of Business and Psychology, 19(4), 429-459. http://dx.doi.org/10.1007/s10869-005-4518-2

Stavros, J., \& Wooten, L. (2012). Positive strategy: Creating and sustaining strengthsbased strategy that SOARs and performs. In K.S. Cameron, \& G.M. Spreitzer (Eds.) The Oxford handbook of positive organizational scholarship (pp. 824-842). New York, NY: Oxford University Press.

Strebel, P. (1996). Why do employees resist change? Harvard Business Review, 74(3), $86-92$.

Szabla, D.B. (2007). A multidimensional view of resistance to organizational change Exploring cognitive, emotional, and intentional responses to planned changed across perceived change leadership strategies. Human Resource Development Quarterly, 18(4), 525-558. http://dx.doi.org/10.1002/hrdq.1218

Van den Heuvel, S., \& Schalk, R. (2009). The relationship between fulfilment of the psychological contract and resistance to change during organizational transformations. Social Science Information, 48(2), 283-313. http://dx.doi. org/10.1177/0539018409102415

Weick, K.E., \& Quinn, R.E. (1999). Organizational change and development. Annual Review of Psychology, 50, 361-386. http://dx.doi.org/10.1146/annurev. psych.50.1.361

Youssef, C.M., \& Luthans, F. (2007). Positive organizational behaviour in the workplace: The impact of hope, optimism, and resilience. Journal of Management, 33(5), 774-800. http://dx.doi.org/10.1177/0149206307305562

Youssef, C.M., \& Luthans, F. (2012). Psychological capital: Meaning, findings, and future directions. In K.S. Cameron, \& G.M. Spreitzer (Eds.), The Oxford handbook
of positive organizational scholarship (pp. 17-27). New York, NY: Oxford University of positive
Press.

Zhong, L. (2007). Effects of psychological capital on employees' job performance, organizational commitment, and organizational citizenship behaviour. Acta Psychologica Sinica, 39(2), 328-334. 